\title{
Histórias de aprendizagem e gestão organizacional: uma abordagem ontológica e hermenêutica
}

\author{
Gentil José de Lucena Filho \\ Ph.D. em Systems Design (University of Waterloo / Canadá); \\ professor / pesquisador do Mestrado em Gestão do Conhecimento \\ Tecnologia da Informação da Universidade Católica de Brasília. \\ E-mail: glucena@pos.ucb.br
}

\section{Margarita Maria Morales Villegas}

Engenheira; especialista em Ontologia da Linguagem (UCB) e Coach Ontológico Certificada (Newfield Consulting). Construindo Juntos Coaching, Treinamento e Consultoria.

E-mail:margarita@construindojuntos.com.br

\section{Sheila da Costa Oliveira}

Mestre em teoria da literatura; D.Sc. em Informática na Educação (UFRGS); professora doutora na Universidade Católica de Brasília. E-mail: sheila@ucb.br

\section{Resumo}

Neste trabalho, partimos de uma história de aprendizagem (HA) já escrita no formato original (segundo desenho originalmente formulado no Centro de Aprendizagem Organizacional do MIT) a qual foi objeto de uma dissertação no Mestrado em Gestão de Conhecimento e Tecnologia da Informação da Universidade Católica de Brasília. Analisamo-la com o objetivo de evidenciar se a mesma tem impacto na aprendizagem organizacional e se constitui instrumento para a gestão organizacional. Para a análise, utilizamos duas abordagens - a Ontologia da Linguagem de Flores / Echeverría, em uma acepção filosófica do termo "ontologia" (diferente da acepção usual comumente utilizada nas ciências de computação e informação), e a Teoria da Interpretação de Ricoeur como meio de verificação de evidência de aprendizagem, tanto em nível de primeira ordem, quanto em nível de segunda ordem. Especificamente, os fenômenos observados são declarações de aprendizagem, tipologias conversacionais e fluxos emocionais presentes na narrativa que constitui a HA.

\section{Palavras-chave}

História de aprendizagem. Gestão organizacional. Ontologia da linguagem. Teoria da interpretação. Aprendizagem. Conversações.

Stories on learning and organizational management: an ontological and hermeneutical approach

\section{Abstract \\ This paper is based on a Story on Learning (according to an original work written in the Organizational Learning Center of Massachusetts Institute of Technology - MIT), which was the subject of a Master Degree dissertation on Knowledge Management and Information Technology, Catholic University of Brasilia. The analysis of this topic is to prove that it has an impact on the organizational learning and that it is an important instrument for Organizational Management. Two different approaches are analyzed: the Ontology of Language by Flores/Echeverría (ontology, a philosophy term, has here a different acceptation from the one used in Computer and Information Science) and Theory of Interpretation by Ricoeur, as a means for verifying the evidence of learning, both on first order level and second order. The conclusion is that the phenomena observed are statements of learning, conversational typologies and emotional flows present in the narratives of the story on learning. \\ Keywords}

Learning history. Organizational management. Ontology of language. Interpretation theory. Learning. Conversations.

\section{INTRODUÇÃO}

As histórias como instrumentos de aprendizagem acompanham as origens sociais do ser humano, na tradição oral e escrita. Sempre que uma historia é contada, fala dos atores e dos feitos em contexto particular e apresenta experiências que contribuem para a aprendizagem de narradores, leitores ou ouvintes. Segundo o contexto no qual é criada/escutada, pode gerar espaços de reflexão do passado e inspiração para a transformação do futuro. Seu papel tem mudado através do tempo e evidencia, entre outros aspectos, processos de transformação humana.

Segundo Echeverría (2003, p.20), antes da invenção do alfabeto, os seres humanos viviam na "linguagem do vir-a-ser"; a linguagem e a ação estavam unidas, as histórias narravam as ações dos atores e, dessa maneira, aprendia-se, por exemplo, sobre o que era coragem ou compaixão. Contudo, o alfabeto separou o narrador da linguagem e da ação, e o surgimento do texto escrito produziu a mudança da linguagem do vir-a-ser para uma linguagem das idéias. A reflexão substituiu o relato, e então começamos a nos perguntar sobre os conceitos, dos quais os heróis passaram a ser exemplos; passamos da linguagem do vir-a-ser para a do ser, mudança que trouxe ganhos no desenvolvimento da capacidade de reflexão, do pensamento racional e científico, da lógica e da filosofia, consumando-se a distinção entre teoria e prática (ECHEVERRÍA, 2003, p. 21).

Não obstante, mesmo com essa separação, as histórias mantêm e revelam seu potencial de aprendizagem, constituindo objeto de diversas áreas do conhecimento. Encontramos termos como "contadores de histórias" (storytellers) e "fazedores de histórias" (storymakers), utilizados por pesquisadores como Todorov (1979), na literatura, Labov e Waletsky (1967), na lingüística; Schafer (2005), na psicanálise, Bruner (1986), na psicologia; Reissman (1993), em estudos sociais, Abma (1998), na saúde, e Geertz (1983), na antropologia; ou Brown (2001) na tecnologia da informação e Senge (1990) na aprendizagem organizacional.

No contexto da análise aqui realizada, entendemos a aprendizagem como uma ação dirigida a aumentar nossa capacidade de ação. "Que fizemos? O que deixamos de 
fazer? O que poderíamos fazer diferente?" são perguntas freqüentes neste nível de aprendizagem, denominada por Chris Argyris (1993) aprendizado de laço simples, ou por Echeverría (2003) de aprendizado no nível da ação. Nesse nível, revisam-se as ações e verifica-se o que é possível fazer para mudar resultados. Ambos os autores reconhecem que, em algumas oportunidades, o repertório de possíveis ações se esgota: chega-se ao ponto em que, no nível específico das ações, não há mais nada a fazer e não é possível aprender mais.

Pode também ocorrer a abertura para uma aprendizagem mais profunda, percebendo-se que as ações do nível anterior dependem do tipo de observador que se é, gerando, com isso, uma possibilidade de aprendizado de laço duplo, conforme Argyris (1993), ou, conforme Echeverría (2003), aprendizado no nível do observador. Neste nível, revisam-se os pressupostos, modelos e valores vigentes que levaram às ações, observando sua estrutura de coerência nos domínios da linguagem, da emocionalidade e do corpo. A aprendizagem nesse nível possibilita novo leque de ações. A isto, Echeverría (2005) chama de aprendizagem transformacional.

Com base nesses pressupostos, este trabalho tem por propósito analisar a narrativa de uma história de aprendizagem (HA): uma história vivida/observada por personagens reais e que gera, durante o seu desenvolvimento, oportunidades de aprendizado, aproveitadas ou não pelos participantes / observadores, tornando-a um possível instrumento de gestão organizacional.

A criação de uma HA decorre basicamente de "pessoas" (participantes / historiadores) que, em sua constante interação com o ambiente (contexto) no qual se ancoram as experiências demarcadoras do enredo, elaboram impressões e conferem / atribuem significado pessoal a essas mesmas experiências (interpretam).

O uso de HA no contexto da gestão é ainda insipiente, embora seu processo seja caracterizado pela coexistência de relatos de experiências, interpretações, registros, compreensão e aprendizagem, entre outros, e constituído de planejamento, pesquisa reflexiva, destilação, escrita, validação, disseminação e publicação. No presente texto, destacamos pesquisa reflexiva, destilação e escrita da HA, atividades marcadas, entre outros aspectos, por uma característica tipicamente interpretativa, tanto por parte das fontes reveladoras dos relatos (os participantes da história), quanto daquele(s) a quem cabe escutá-los e registrá-los.
Conforme descrito em Torres et alii (2006), na pesquisa reflexiva pessoas são entrevistadas, perspectivas diversas são colhidas, documentos são examinados, observações são realizadas etc. $\mathrm{Na}$ etapa de destilação, a partir dos dados coletados, o historiador / narrador, mediante interpretações, seleciona o que julga relevante, sistematiza o que foi compreendido e analisa suas implicações. Por fim, na etapa da escrita, sob o conceito antropológico de histórias contadas conjuntamente, o documento da HA é produzido, procurando incorporar experiências e emoções dos atores à perspectiva mais abrangente do(s) historiador(es).

\section{ESTRUTURACุÃO E FORMATAÇÃO DO PROCESSO DE ANÁLISE}

Um dos postulados básicos da ontologia da linguagem (OL) é o caráter generativo da linguagem (FLORES, 1979; ECHEVERRÍA, 2003, p. 33-36), isto é, linguagem é ação. Ainda segundo Echeverría (2003), citando o filósofo britânico J. L. Austin (p. 141-142), numa ação lingüística estão subjacentes três níveis de subações: locucionário (ato de articular as palavras em uma narrativa); ilocucionário (ação compreendida na articulação utilizada, o que é dito); perlocucionário (conseqüências dessa ação).

Na escrita da HA, observa-se, em sua formatação (figura 1) que os níveis locucionário (forma) e ilocucionário (significado) aparecem explicitamente na narrativa. Já o nível perlocucionário (conseqüências das ações), ainda que possa ser inferido, não aparece explicitamente na narrativa.

\section{FIGURA 1}

Formato de uma página típica de um documento de história de aprendizagem

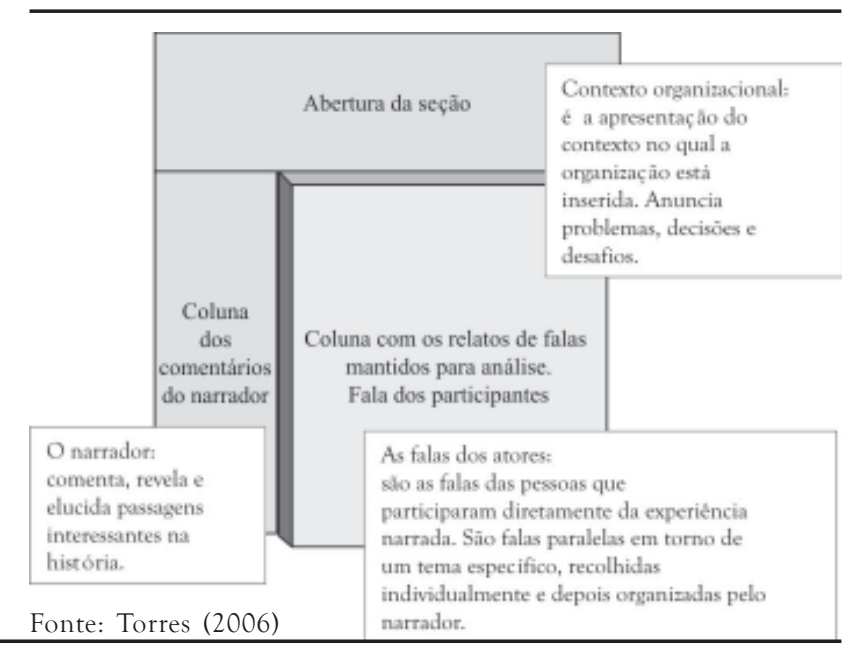


Na HA original (figura 1), a narrativa é organizada em um formato de duas linhas, a segunda dividida em duas colunas, com as respectivas articulações e significados. Para a análise, inicialmente adotamos um formato recursivo (tipo de "História da História da Aprendizagem - HHA”). Esse formato, adaptado do formato original (figura 1), é mostrado na figura 2. Ou seja, acrescentamos dois elementos: uma linha inicial, em que introduzimos observações gerais a respeito do contexto, e uma coluna lateral esquerda, onde comentamos falas dos participantes ou do narrador e fazemos observações, apontando o que consideramos pertinente à análise. Falas que não estão em foco foram eliminadas e sinalizadas com colchetes [...].

Essa escolha pretende indicar que nem a HA nem as análises que dela venham ser feitas podem ser consideradas verdades absolutas. Em qualquer dos casos, trata-se apenas de mais uma interpretação, mais um olhar de novos observadores que, ontologicamente, sabem que sua interpretação e compreensão das narrativas são apenas isso: sua interpretação e compreensão do fenômeno em foco, o que decorre diretamente dos referenciais teóricos utilizados e traz outra implicação: outros observadores (futuros leitores, indivíduos ou organizações) que eventualmente venham a se utilizar desta HA, não importando quem sejam, poderão posicionar-se e decidir quais conhecimentos / distinções expressos na HA são relevantes e significativos para suas respectivas aprendizagens, bem como associar esses conhecimentos / distinções ao(s) contextos(s) em que a HA acontece.
FIGURA 2

Formato para análise das HA utilizado no livro

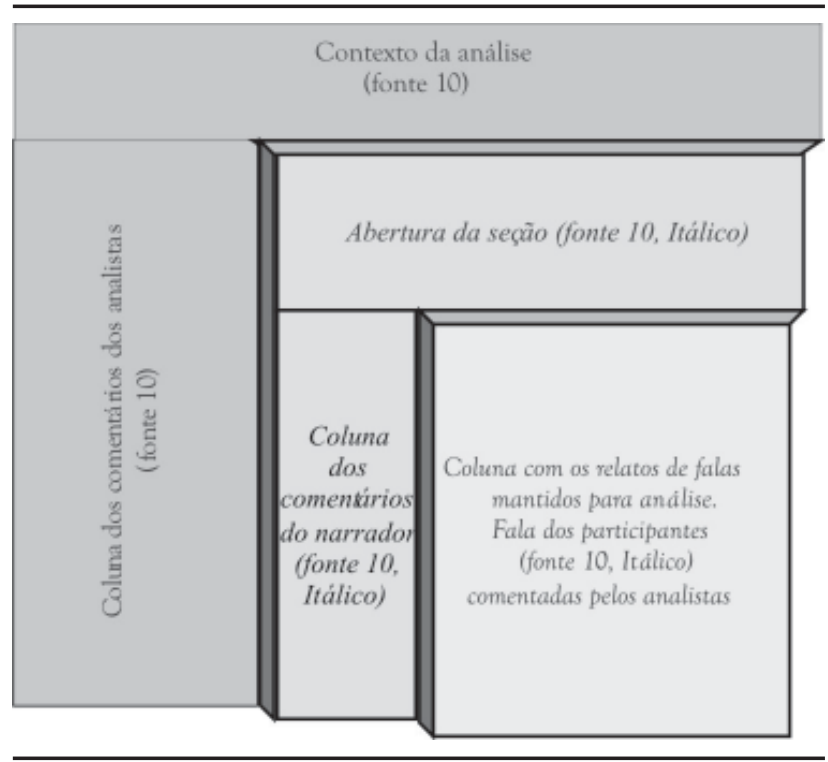

formato original, em colunas lado a lado, apresentado na figura 2, gera aumento no número de páginas e algumas dificuldades no armazenamento de arquivos eletrônicos. Portanto, para fins de publicação, os autores do presente trabalho optaram por modificar o modelo apresentado na coluna da esquerda, adaptando-o, sem perda de conteúdo, para o formato da direita, conforme descrito na figura 3 .

\section{FIGURA 3}

Adaptação do modelo original de uma história de aprendizagem

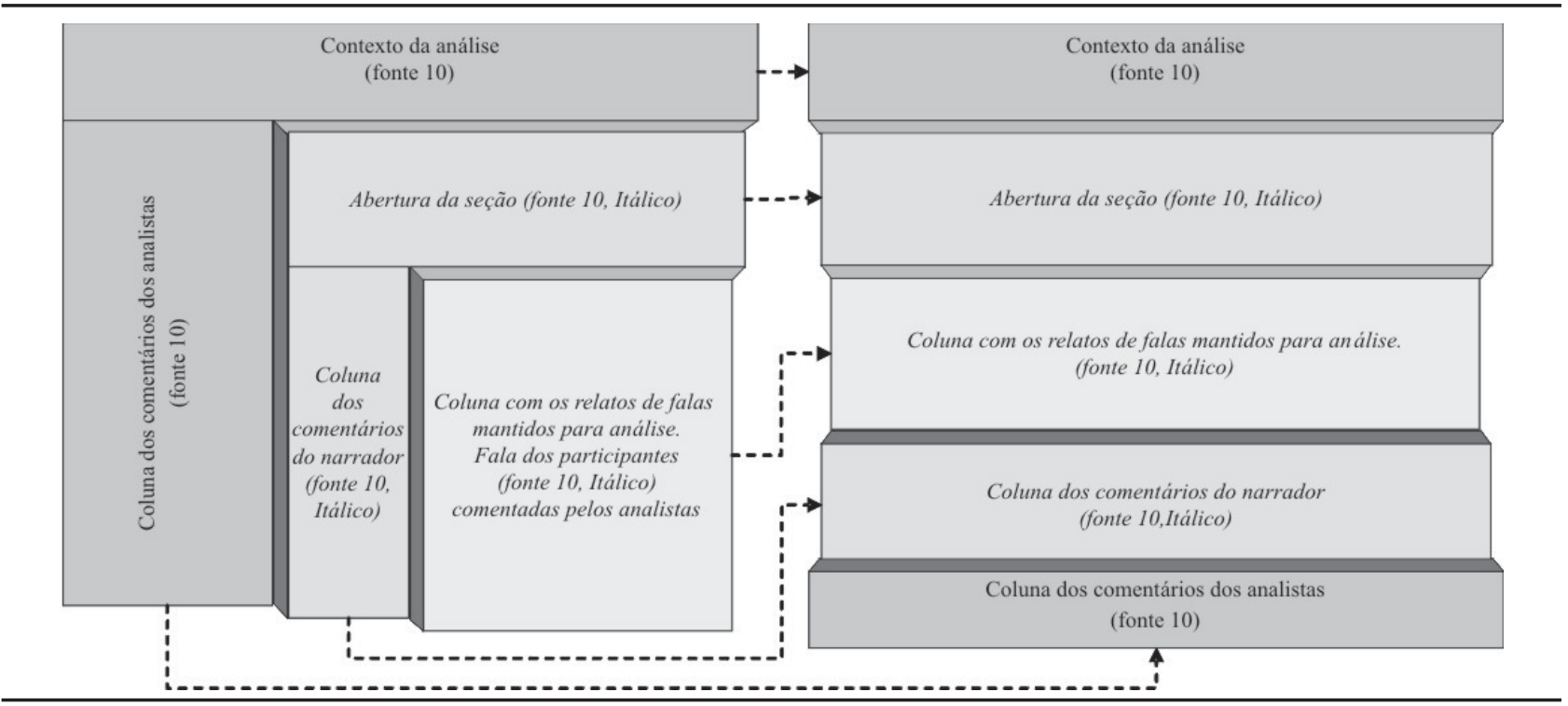


Não constarão da presente análise o processo de construção de uma HA nem sua disseminação. Para o primeiro aspecto, processo de construção da HA analisada, remetemos a Torres et alii (2008). Já sobre a disseminação, sabe-se que os autores de Torres et alii $(2008)^{1}$ cogitam de tratar em nova publicação.

Por fim, cumpre ressaltar as perguntas centrais a que se buscará responder com a análise. A partir do pressuposto de que linguagem é ação, de que narrativas são artefatos lingüísticos constituídos através de ações configuradas em múltiplos níveis e que, em última instância, histórias de aprendizagem acontecem sob a forma de narrativas, cabe perguntar:

a) Uma HA, de fato, provê aprendizagem para aqueles que dela participam e / ou dela se utilizam?

b) A narrativa revela / poderá revelar aprendizado por parte daqueles que dela participaram?

c) Se sim, por parte de quem?

d) Que personagens se destacam nesse sentido?

e) A aprendizagem verificada se limita ao nível individual ou há evidências disso no nível organizacional?

f) Que conseqüências esse aprendizado gerou / poderá gerar?

\section{ABORDAGEM FILOSÓFICO-TEÓRICO- METODOLÓGICA}

Para o caso da análise em foco, a sustentação dessa abordagem é feita a partir da hermenêutica e teoria de interpretação (HTI) do filósofo francês Paul Ricoeur (1991, 1995) e da ontologia da linguagem (FLORES, 1979; ECHEVERRÍA, 1994), notando-se que o elo entre ambas é precisamente a natureza humana do fenômeno de contar histórias e de aprender com elas.

\section{Da perspectiva hermenêutica e da teoria da interpretação de Ricoeur}

De acordo com Geanellos (2000), a HTI de Paul Ricoeur (1973, 1974, 1991, 1995) assenta-se em duas dimensões: a) visa a explicar uma epistemologia da interpretação segundo a qual a interpretação textual seria a principal finalidade da hermenêutica, levando em conta linguagem,

\footnotetext{
${ }^{1}$ No prelo, pela Editora Universa, Universidade Católica de Brasília, com lançamento para dezembro de 2008.
}

reflexão, compreensão e self; b) na linha da dimensão ontológica, cuida de acentuar a conjunção de intérprete (ou observador) e interpretação no processo interpretativo, evitando a cada vez mais insustentável separação cartesiana entre sujeito e objeto. Ainda segundo Geanellos (2000), para Ricoeur a interpretação seria o lugar de conjunção entre linguagem e experiência. Isso, no caso da HA em estudo neste trabalho, é especialmente evidente quando se percebe, por exemplo, que as interações realizadas entre narrador(es) e participantes da HA (sob a forma de entrevistas) resultam, literalmente, em narrativas por meio das quais se conjugam linguagem e as experiências vivenciadas pelos participantes: textos ontologicamente interpretados pelos respectivos observadores envolvidos no fenômeno (história de aprendizagem) que é objeto do relato.

\section{Da perspectiva ontológica}

A perspectiva ontológica utilizada neste trabalho segue a acepção filosófica do termo, diferente da comumente utilizada na ciência da computação e na ciência da informação. Nestas últimas, o termo ontologia é entendido como uma representação formal e explícita de um conjunto de conceitos, suas definições e suas interrelações dentro de um domínio (USCHOLD; GRUNINGER, 1996; GUARINO, 1998). Nesse contexto, a ontologia é usada para explorar / raciocinar sobre propriedades daquele domínio, podendo, com isso, inclusive, ser usada para definir o domínio. $\mathrm{Na}$ perspectiva filosófica, compreende-se a ontologia como um campo de estudos da natureza do ser (being), da existência ou da realidade em geral. Nessa perspectiva, de maneira geral, usa-se a ontologia para caracterizar tipos e estruturas de objetos, propriedades, eventos, processos e relações referentes ao ser ou realidade que se quer representar (FONSECA, 2007).

No contexto específico deste trabalho, usamos a ontologia segundo a perspectiva filosófica descrita por Echeverría, (2003). Nessa obra, o autor apresenta o termo ontologia como derivado de uma tradição inaugurada pelo filósofo alemão Martin Heidegger, para quem a noção de ontologia estava relacionada ao que ele chamava de Dasein, em suas investigações sobre o que significa ser humano. Nesse sentido, "a ontologia faz referência à nossa compreensão genérica - nossa interpretação - do que significa ser humano" (ECHEVERRÍA, 2003, p. 28).

Dando seguimento a essa tradição filosófica inaugurada por Heidegger, podemos identificar várias contribuições decorrentes de campos os mais diversos da ciência, tais 
como a epistemologia das ciências e da hermenêutica de Ricoeur, a teoria sistêmica de Bertalanfy, a autopoiese de Maturana, o construtivismo de Vigotsky e Piaget, a aprendizagem organizacional de Argyris e Schön, entre outras.

Nesse mesmo movimento, surge o trabalho de Fernando Flores (FLORES, 1979), mais tarde expandido e amplamente divulgado por Echeverría (2003), em torno de uma ontologia da linguagem (OL), a partir de cuja interpretação "os seres humanos são seres linguísticos".

O que se espera da perspectiva ontológica, neste trabalho? Com base nas pesquisas de Flores e Echeverría (2003), utilizamo-nos da Ontologia da Linguagem, principalmente, como um suporte metodológico à interpretação sistemática das interlocuções realizadas entre narrador(es) e participantes da HA contada, e desta, enquanto narrativa textual, com seus analistas, para evidenciar que uma HA, ao ser contada ou narrada (mesmo que não disseminada), proporciona aprendizagem para aqueles que a contam / narram e para os que a lêem / escutam, sejam pessoas isoladas ou organizações.

Segundo Echeverría (2003), a história geralmente se constitui a partir de narrativa lingüística e é compreendida como fenômeno humano, social, que surge no processo de interação, no jogo coletivo de indivíduos que, juntos, coordenam ações (ECHEVERRÍA, 2003, p. 362). Como tal, quando falamos de histórias, estamos dizendo que se inserem em um discurso histórico, em uma meta-história particular caracterizada pela coerência de uma comunidade que vive numa determinada linguagem, coerência que pode não se revelar no contexto de outra comunidade que viva noutra linguagem (ECHEVERRÍA, 2003, p. 363). Assim, as histórias proporcionam aprendizagem à medida que revelam estruturas de coerência nas quais estão incluídos o tempo e os feitos dos atores nelas envolvidos. Ao revelarem "ações" em contextos determinados, permitem sinalizar caminhos para possibilitar que novas estruturas surjam nos contextos dos seus leitores e / ou ouvintes, pois, como dito antes, contar histórias não significa meramente descrever o passado, mas também (e principalmente?) construir ou (re)criar o futuro.

\section{Do observador (intérprete) e da aprendizagem}

Uma das principais distinções da OL é o "Observador". Segundo (ECHEVERRÍA, 2005, p. 212), cada um de nós, como seres humanos, damos sentido ao que acontece de uma maneira diferente, interpretando o que nos rodeia à nossa própria maneira: "toda consideração feita por um observador fala do tipo de observador que esse observador considera que é"; ao falar ou atuar, revelamos os supostos ontológicos que nos fazem o observador que somos (ECHEVERRÍA, 2005, p. 212).

Outra premissa fundamental da ontologia da linguagem consiste em aprender a observar o tipo de observador que somos, tanto nós mesmos quanto os outros (ECHEVERRÍA, 2005, p. 212), pois todos somos limitados em nossa capacidade de observação, o que se reflete na capacidade de ação. Quando esses limites aparecem e as ações se tornam insuficientes, surge a necessidade de aprender, ou seja, de ampliar nossa capacidade de ação (ECHEVERRÍA, 2005, p. 213).

Echeverría (2005, p.215), expandindo o trabalho sobre o modelo de aprendizagem de Argyris, construiu o que denomina o "Modelo do Observador, a Ação e os Resultados" (figura 4). Um dos objetivos mais importantes da aprendizagem é dissolver os obstáculos que encontramos na nossa capacidade de ação, mudar o tipo de observador que somos, ampliar, expandir ou transformar nossa capacidade de observação e, em conseqüência, nossa capacidade de ação:

\section{FIGURA 4}

Modelo do observador, a ação e os resultados

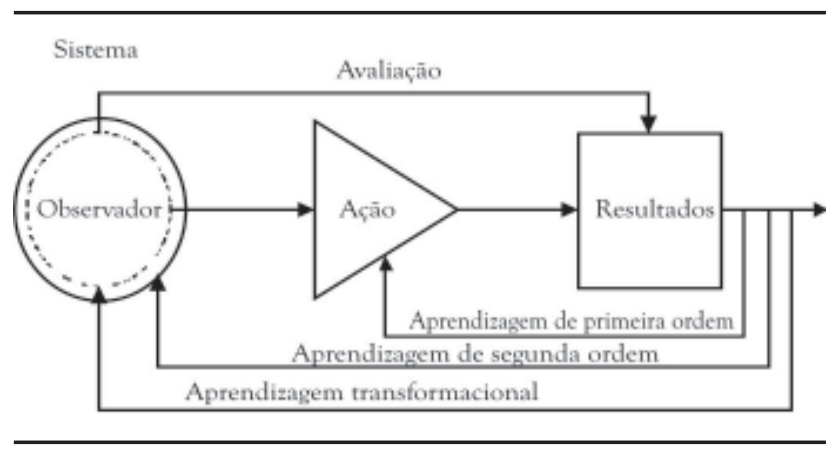

Fonte: Echeverría (2005)

A partir dessas noções de observador e aprendizagem, relacionamo-las com a HTI de Ricoeur (1991, 1995), segundo a qual o processo de interpretação do texto se compõe de quatro movimentos: o distanciamento, a apropriação, a explicação e a compreensão. Por isso, de acordo com ele, compreendemos algo somente quando o compreendamos de uma maneira que dramaticamente mude nossa perspectiva. Em termos ontológicos, isso corresponderia a "até mudar o observador que somos 
do mundo”. É a partir da unificação dessas duas perspectivas (Ricoeur e Echeverría), a que nos referiremos como uma nova perspectiva, que nos aproximamos da HA aqui analisada.

Segundo essa nova perspectiva, o distanciamento se confunde com observar o observador que somos. Já sobre compreensão, em Ricoeur, corresponde ao resultado de um movimento dialético entre distanciamento e apropriação, ao que se atribui o significado de aprendizagem.

\section{O QUE ANALISAMOS}

A partir desses dois autores e das falas dos participantes e dos narradores, observamos três fenômenos na HA: declarações de aprendizagem, tipologias conversacionais e fluxo emocional das equipes.

\section{Declarações de aprendizagem}

Declarações constituem ações lingüísticas responsáveis pela criação de novas realidades. Ao fazer uma declaração, o declarante faz opções e o mundo muda a partir dali, para ele e para outros que estejam no espaço implicado pela declaração (ECHEVERRÍA, 2003, p. 75).

Várias declarações são destacadas nas passagens da HA:

- de abertura: reconhecem a insuficiência, a necessidade de novas decisões e aprendizagens e geram abertura para isso.

- de resistência: indicam a existência de algum processo de resistência à aprendizagem ou à incorporação desta à rotina cotidiana.

- de aprendizagem: evidenciam mudanças realizadas e sugerem aprendizagens, parciais ou imediatas, de primeira ou de segunda ordem (ARGYRIS, 1993).

\section{Tipologias de conversações}

Para o presente caso de análise de HA, queremos evidenciar, no nível da linguagem, o fluxo de conversações na organização. Segundo Echeverría (2003, p. 263), qualquer que seja o problema enfrentado por uma organização, este sempre poderá ser examinado em sua estrutura conversacional. A partir da experiência de um dos autores em atividades de consultoria com a Newfield Network (www.newfield.cl), apresentamos a seguir tipologias de conversações necessárias ao fluxo de aprendizagem organizacional:
- de orientação: conversas à base de declarações fundamentais sobre o futuro desejado da organização, princípios, valores, políticas nutridas pelas ações das diferentes equipes;

- de desenho: conversas à base de declarações sobre como se organiza a organização, definição de processos, papéis e atribuições das equipes, especulação de futuro e conversações de estratégia;

- de implementação: conversações de compromissos, identificação de objetivos, pedidos, ofertas, negociação e implementação das ações, assim como a abertura de maiores redes de colaboração e a solução de problemas;

- de aprendizagem: conversações de avaliação, na qual surgem as perguntas sobre como se está fazendo a organização, sobre o próprio fluxo conversacional e a rede de relacionamentos que a constitui.

\section{Fluxo emocional}

Novamente baseados na OL, podemos observar o domínio da emocionalidade, que nos condiciona para a ação, tornando algumas ações possíveis ou impossíveis (ECHEVERRÍA, 1994, p.259), e que está profundamente ligado com a aprendizagem. Segundo Echeverría (1994), existem quatro estados de ânimo básicos para a ação:

- ressentimento / paz: dois estados de ânimo decisivos perante as facticidades da vida, no domínio pessoal ou organizacional. Ou a pessoa resiste e se opõe ao acontecimento, gerando o ressentimento, ou aceita o ocorrido e fica em paz;

- resignação/ entusiasmo: dois estados de ânimo que, perante as possibilidades, no domínio pessoal ou organizacional, apresentam-se à pessoa, que resiste e se opõe a essa possibilidade, gerando um estado de resignação; ou aceita a possibilidade e se dispõe com ambição e entusiasmo para o futuro.

São esses os elementos que analisaremos na história a seguir.

\section{ANÁLISE DA HISTÓRIA DE APRENDIZAGEM DO SISTEMA DE INFORMAÇÕES AGRÍCOLAS E ABASTECIMENTO}

A história de aprendizagem que se segue foi escrita primeiramente no formato original, desenhado no Centro de Aprendizagem Organizacional do MIT. Constituiu objeto da dissertação de mestrado de Torres 
(2006) no Programa em Gestão de Conhecimento e Tecnologia da Informação da Universidade Católica de Brasília e narra a implantação de um sistema de informações voltado para o agronegócio e o abastecimento.

O formato utilizado na análise, como descrito na figura 2, e modificado aqui para fins de publicação, conforme anunciado anteriormente na figura 3, corresponde ao que se segue.

\section{Contexto da análise}

Esta história surge a partir da declaração do objetivo estratégico de uma organização definido como prioridade 1. Essa abertura reconhece a existência de conversações de orientação, pressupõe a existência de um plano estratégico e apresenta riqueza em diversidade de visões de futuro. Observam-se visões micro e visões macro, estratégicas e táticas, em torno do mesmo projeto. O espaço emocional escutado é o da aceitação do desafio, da acolhida ao novo projeto. Existem dificuldades em termos de confiança entre as equipes e a autoridade, de propriedade da informação e falta clareza das condições de satisfação do sistema. O historiador, de forma muito apropriada, articula atos ilocucionários (dependência de pessoas, falta de confiança, problemas de comunicação, sentimento de propriedade) implícitos nas locuções correspondentes, retratadas nas falas dos participantes.

\section{Início de tudo: informação}

A organização é uma empresa que tem em sua cultura a percepção de que sua principal matéria-prima é a informação. A informação sobre indicadores de agronegócio e abastecimento, até então, é tratada por diversas áreas que, em função da história de fusão da organização, têm problemas de comunicação. Por isso, com o passar do tempo, as áreas passaram a gerar informações redundantes, cada uma da maneira que achava correta. $\mathrm{O}$ projeto do Sistema de Informações de Agronegócio e Abastecimento (SIA) tem como objetivo colocar ordem neste contexto.

SUPERINTENDENTE: A partir [...] do planejamento estratégico da organização e com base nele, alguns objetivos foram definidos, que é exatamente a organização ser referência como provedora de informações e conhecimentos no setor agrícola de abastecimento. Então, para exercer de fato essa função, esse papel, seria necessária uma reformulação interna. Dentro dessa linha, de qualificar a informação, de ter um crédito, uma validação dessa informação é subsidiar de fato as propostas e as políticas, é que se enquadra o SIA, motivo pelo qual foi estabelecido como prioritário.

GESTOR: [...] O próprio agropreço: ele está aqui no servidor, mas não está na web. Para toda demanda externa, as pessoas têm de nos solicitar. A idéia é que isso esteja em um ambiente web no qual qualquer pessoa, em qualquer parte do Brasil, possa ter informação de preços, desde o mercado produtor, varejo, atacado, o preço na indústria, o preço no mercado externo, outras informações, para onde o Brasil está exportando, a balança do agronegócio que acompanhamos. Também parte das operações da organização, pois ela tem vários instrumentos que também não estão disponíveis de uma forma sistemática.

SUPERINTENDENTE: [...] São informações essenciais, [...] que precisam ser trabalhadas para subsidiar todo trabalho de planejamento de como o governo vai intervir no mercado: é hora de intervir? não é hora de intervir? que tipo de instrumentos nós deveremos utilizar naquele determinado momento?

GERENTE DE SISTEMAS: [...]O que acontece é que as informações existem de alguma forma, elas estão muito espalhadas e muitas delas não têm a consistência que deveriam ter. [...]

SUPERINTENDENTE: A organização passou por um processo de enxugamento, no qual muito do conhecimento foi embora. Por não termos nada que preservasse a memória organizacional, tivemos esse prejuízo [do conhecimento].

Acabamos tendo aí uma duplicidade de atividade: as informações captadas pela área 1 não eram utilizadas pela área 2 e os próprios técnicos de produto acabavam por criar suas próprias redes de informantes, fazendo desse outro canal uma duplicidade de atividade por não ter, a informação captada pela área 1, o crédito, a confiabilidade e a tempestividade necessários. [...]

ANALISTA DE NEGÓCIO 1: Foi-nos colocada a necessidade de fazer uma modelagem de negócio de um sistema que conseguisse coletar, tratar e disseminar as informações do setor agrícola e de abastecimento.

Houve bastante restrição das pessoas neste início, porque a área $\mathrm{X}$ dizia que a área $\mathrm{Y}$ deveria gerar algumas informações para eles, a área acabava não gerando a informação, então a área solicitante acabava, pelos seus 
próprios meios, indo atrás da informação. Isso a gente constatou à medida que foram feitas as entrevistas. Percebíamos que a mesma informação era capturada tratada e disseminada de diferentes maneiras em diferentes áreas. [...]

Objetivo do sistema: organizar e disponibilizar as informações, cumprindo o objetivo estratégico definido para a organização.

Até então, existe uma dependência das pessoas que sabem trabalhar as informações. Existe também a falta de confiança entre as áreas envolvidas no processo de gestão das informações, problemas de comunicação e um sentimento de "propriedade" da informação.

A organização contrata um grupo de consultores para iniciar o projeto pela modelagem dos processos de negócio. Os problemas sistêmicos de comunicação se manifestam nas restrições e na falta de estrutura das informações, apesar da sua importância estratégica. Cabe agora aos consultores externos resolver esses problemas.

Foi mencionado o objetivo estratégico por um participante e pelo historiador. É reconhecida a prioridade da necessidade de aprendizagem. Porém, esse caráter estratégico foi mencionado uma única vez, o que pode evidenciar a falta de compartilhamento de visão.

Explicita-se uma macronecessidade que será resolvida por intermédio do trabalho do grupo no qual se vivencia uma quebra na confiança. Reconhece-se a existência de rotinas que sustentam a falta de confiança, como é o caso da duplicação da informação.

A consultoria poderá gerar as conversações para reconstruir a confiança entre os grupos?

Definição do que se quer ou do que se necessita: O último comentário do historiador, no trecho anterior, revela a natureza sistêmica do problema. Decide-se contratar uma consultoria externa para apoiar a realização do projeto. Nas falas dos participantes não são especificadas as condições de satisfação do pedido à consultoria. Não podemos afirmar que foram realizadas ou não, mas, na execução do projeto, alguns problemas sugerem a falta dessas especificações. Em uma análise ontológica, cabe perguntar: seria possível por parte da equipe ou da consultoria saber o que falta em um projeto inovador? Aqui, podemos observar como o fluxo emocional decai para ressentimento, porque só agora, quando o grupo sabe do que aconteceu, percebe que faltava o escopo do projeto. São evidentes as dificuldades para aceitar em paz que em projetos desse tipo, é possível não ter uma noção clara dos objetivos. Visto assim, deixar que o escopo seja definido em conjunto é uma questão de estratégia e também dos próprios limites de conhecimento e competências do grupo.

\section{Qual o problema?}

A equipe de consultoria foi contratada e o projeto iniciado. Todos os comprometimentos profissionais, pessoais e políticos foram feitos. Mas o escopo do projeto não foi delimitado.

ANALISTA DE NEGÓCIO 2: O projeto tinha como escopo a modelagem do sistema de informações agrícolas e abastecimento. Só que o que era sistema de informações agrícolas e abastecimento sofreu várias mudanças ao longo do projeto. $\mathrm{O}$ início do projeto se caracterizou pelo baixo conhecimento sobre o negócio, tanto por parte da equipe de consultoria, quanto da equipe de coordenação e gestores do projeto. Existia uma nuvem a respeito do que era o sistema.

Não conhecíamos o domínio do problema, não sabíamos qual tamanho teria o SIA.

ANALISTA DE NEGÓCIO 1: Na época que começou o projeto, o escopo não era muito claro para o próprio usuário que estava envolvido, então tivemos um trabalho muito grande nos reunindo com o grupo de usuários para que eles conseguissem delimitar qual era o escopo deste projeto.

O escopo não estava definido na mente dos envolvidos. Isso era, de certa forma, deliberado. O plano era que o fechamento do escopo seria feito em conjunto com os usuários interessados. Essa foi uma boa estratégia?

O desconhecimento do contexto e do próprio objeto tensionam as possibilidades de aprendizagem. As maneiras como os envolvidos lidam com essa tensão demonstram uma resistência para a aprendizagem evidenciada quando se buscam culpáveis (o desconhecimento e a falta de escopo) e não acontecem conversações de desenho que permitam lidar com estes fatos.

Começou a execução: Uma vez criado o contexto da necessidade do SIA e feitos os pedidos à equipe da consultoria, começa a execução das atividades. Primeira ação: reunir todos e conversar! As expectativas eram altas e ficaram frustradas. Pelos relatos, essa primeira ação permitiu que as pessoas expressassem suas emoções e 
descontentamento, sua frustração. Pela surpresa desse resultado para a consultoria e para os gestores do projeto, os indícios são de que faltou espaço para conversar sobre as emocionalidades das equipes. Isso revela que a Organização é um tipo de observador que não leva em consideração, ou que não reconhece a importância do espaço emocional como viabilizador para suas ações. É interessante que, nas falas, as lições aprendidas são encaminhadas para evitar que essas coisas aconteçam novamente. Falta, nas conversações de desenho e no processo de aprendizagem incluir, o espaço emocional. Percebe-se um fluxo emocional que se orienta para o ressentimento, pela não-aceitação da necessidade de um espaço para conversações sobre construção de relacionamentos, e para a resignação: é assim mesmo e não vai mudar.

\section{Workshop Inicial: começando com o pé esquerdo}

A primeira ação no projeto foi o Workshop Inicial, que tinha como objetivo definir o escopo do projeto. A equipe de consultoria esperava absorver conceitos de alto nível, vocabulário e ter uma visão geral dos processos envolvidos. Para isso, foi estabelecido um roteiro que pretendia avaliar diversos aspectos da organização e foi utilizada uma ferramenta de apoio para gerar o mapa de idéias. Foram convocadas pessoas de todas as áreas que tratavam de informações agrícolas, o que na organização quer dizer quase todo mundo, para meio dia de conversas. Por não ter havido nenhum levantamento prévio, mapeamento de expectativas, a consultoria é pega de surpresa com os perfis e os ânimos manifestados na reunião.

GERENTE DE SISTEMAS: [...] Estruturamos o workshop de forma que pudesse englobar várias áreas, [...] Aí eu acho que houve uma mistura muito grande de usuários, uma confusão em termos de o que seria o projeto, as expectativas não estavam bem alinhadas.

SUPERINTENDENTE: [...] Como não se faziam há muitos anos] investimentos na área de TI, as áreas encontraram várias dificuldades para deflagrar processos]. Então, o processo caiu em descrédito: "eu já vi essa novela antes, não foi uma, nem duas, nem três vezes".

ANALISTA DE NEGÓCIO 2: [...] foi uma sessão de workshop que, a meu ver, não foi bem- sucedida.

GERENTE DE SISTEMAS: [...]. Assim, já fomos com a proposta um pouco ampla para o tipo de workshop, o que acabou não dando certo. Foi uma confusão em função disso. Como o escopo não estava muito bem delimitado, a gente tinha a idéia de delimitar o sistema neste workshop. A coisa acabou extrapolando para [a discussão de] outros sistemas que teoricamente não tem a ver com o SIA.

ANALISTA DE NEGÓCIO 2: Por causa das incertezas, não foi possível conduzir de forma correta, com tantos anseios, com tantos perfis diferentes e com tanto desconhecimento nosso sobre o assunto. Os resultados não foram satisfatórios.

Cada grupo desejava muito do projeto e cada um tinha uma visão diferenciada, muitas vezes conflitante. Os conflitos tiveram um espaço significativo dentro daquela sessão de workshop. Foi muito difícil conduzir.

SUPERINTENDENTE: Os consultores foram avisados previamente que havia problemas de relacionamento entre as áreas.

ANALISTA DE NEGÓCIO 1: O que não sabíamos no workshop era que existia um problema grande na organização, das pessoas se julgarem donos da informação, das atividades...

Eu tenho hoje a clara visão que não foi a decisão acertada reunir todas as pessoas naquele momento. Nós, os consultores, não tínhamos conhecimento da existência dos problemas que vimos no workshop.

ANALISTA DE NEGÓCIO 1: Para os resultados que esperávamos, foi um workshop conduzido de forma estruturada, obtivemos os produtos do workshop, mas o resultado desses produtos não agregou muito para o conhecimento que a gente precisava adquirir naquele momento.

SUPERINTENDENTE: Não tivemos resultado que se esperava. Saímos de lá, levantamos algumas questões, mas as pessoas estavam muito críticas, alguns muito dispersas fazendo piadinhas. Isoladamente foi um evento um pouco complicado.

GERENTE DE SISTEMAS: [...] O que aconteceu foi uma confusão. As pessoas confundiram o objetivo maior, que seria o desenvolvimento do sistema, com a solução de problemas específicos de cada área.

Em termos da consultoria, ela ficou de saia justa. Era o primeiro workshop, não se tinha uma intimidade da consultoria com a Casa. Estamos tentando ajustar isto no próximo projeto, ou seja, a consultoria andar mais para chegar no primeiro workshop e ter condições de conduzir com mais segurança. Em termos do próprio 
sistema, não se avançou muito. [...] Do ponto de vista do usuário, apesar da bagunça, tiveram a impressão de ter saído com algum conteúdo dali. Foi positivo.

ANALISTA DE NEGÓCIO 2: O aprendizado que a gente tirou disso foi que precisávamos estar mais bem preparados, que as expectativas dos usuários precisavam estar mais bem definidas antes do workshop. O workshop inicial deve ter uma preparação do ponto de vista de domínio do problema e, como o domínio do problema naquela época não estava bem sedimentado entre as pessoas que estavam participando, resultou em alguns problemas no projeto.

Muita gente, problemas de relacionamento, muitas expectativas e objetivos que não estavam claros. O workshop nasceu com poucas chances de dar certo. Como isso poderia ter sido previsto?

O resultado desta ação foi avaliado pela consultoria e pelos gestores do projeto como negativa, frustrante, que faltou conhecimento e desenho. Por outro lado, em que pese o não-reconhecimento da consultoria e dos gestores do projeto, observam-se indícios de resultados importantes: foram reconhecidas as dificuldades entre as áreas, as diferenças nas visões e os conflitos existentes. Isso, eventualmente, permitiria à consultoria o redesenho da sua intervenção. De qualquer forma, houve reconhecimento de que, para os usuários, o resultado foi positivo.

No entanto, a percepção de que os resultados, no geral, foram negativos restringe as possibilidades de aprendizagem. Será que um espaço para reconhecer as dificuldades pode se tornar uma ação efetiva? Será que, no lugar de tentar prever ou evitar este tipo de situação, poderia se inserir ações para desenhar, manejar e gerar situações como essa em projetos futuros?

Levantamento dos processos. A partir de entrevistas com diferentes pessoas, os personagens começam a levantar processos. A ação conversacional é focada na escuta das necessidades dos usuários, apresentando uma emocionalidade de resignação: "não sabemos qual o escopo, agora teremos que escutar tudo de todo mundo". Pela narrativa, parece que as pessoas estão mais focadas em si mesmas, nos próprios problemas, e não têm uma consciência do coletivo, alimentando na equipe da consultoria, ainda mais, o sentimento de perda de tempo nas entrevistas. Contudo, foi possível construir uma visão compartilhada do sistema. A consultoria e a coordenação puderam se alinhar e definir o escopo. $\mathrm{O}$ historiador

reflete sobre as divergências e como evitá-las, mas cabe também refletir se teriam sido mesmo necessárias todas as experiências para criar produtos consensuais e abrir espaços de aprendizagem mais poderosos. Novamente se observa que, uma vez passada a experiência, o grupo apresenta certa facilidade para desqualificar as ações realizadas, não valorizar o que aconteceu; ao mesmo tempo não se evidencia na fala se o grupo costuma trocar feedbacks (principalmente quando negativos) nos momentos necessários.

\section{Levantamento da situação atual: falta de escopo}

Após o Workshop Inicial, o projeto entra na etapa de levantamento dos processos atuais, em reuniões com diversas áreas. No entanto, como o projeto iniciou sem definição do escopo, e como essa tarefa não foi realizada no workshop, a equipe perde um precioso tempo levantando processos antes de delimitar o escopo. A participação de um usuário em especial e a "invenção" de um novo artefato serão peças essenciais para o andamento do projeto.

SUPERINTENDENTE: [...] Quando a pessoa começa a falar sobre, por exemplo, informações de estoques públicos, já começa a buscar informações do processo de gestão de estoques públicos que não faziam parte do escopo do SIA. Dada essa demanda reprimida ao longo dos anos, as pessoas querem que tudo saia simultaneamente, e não é por aí.

ANALISTA DE NEGÓCIO 2: [...]percebemos, após o levantamento da situação atual, que seria praticamente impossível conseguir levantar melhoria de processos, levantar sistemas para atender a esses processos e propor o desenvolvimento de alguns produtos de software, devido ao tamanho que estava se tornando o SIA.

ANALISTA DE NEGÓCIO 1: Depois que identificamos o que era o escopo, vimos que tínhamos seis meses para trabalhar nesse projeto, e nesse prazo não era possível realizar todo o trabalho que estávamos propondo para todas as áreas envolvidas.

GERENTE DE SISTEMAS: [...] A coordenação delimitou o escopo algumas vezes, mas a consultoria não conseguia ver com a mesma clareza o que estava sendo passado a eles.

ANALISTA DE NEGÓCIO 2: [...] a gente conseguiu construir um mapa para tentar delimitar os conceitos que deveriam ser trabalhados no sistema. Esse mapa permitiu que a gente direcionasse o restante das 
entrevistas. Acho que essa reunião foi um marco no desenrolar do projeto, porque foi ali que a gente passou a compreender melhor qual o escopo, ou o contexto do SIA. [...]

ANALISTA DE NEGÓCIO 1: [...]à medida que a gente ia fazendo as entrevistas, os usuários nos davam a visão bem focada na área deles. Quando fizemos esse redimensionamento do escopo ao final do segundo mês, e elegemos as duas principais áreas, parte do trabalho que havíamos feito acabou não sendo evoluído dentro deste projeto.

SUPERINTENDENTE: Eu enxergo que, como não tinha linha de corte, ou como ainda estava obscuro para o usuário e a demanda reprimida era muito grande, acabou jogando-se fora alguns esforços e modelando-se fluxos que não faziam parte do projeto, mas eu entendo isso como um processo natural.

ANALISTA DE NEGÓCIO 2: Nós resolvemos reunir com os principais gestores e esquecemos facilitadores 1 e 2, fizemos uma reunião e delimitamos o escopo desta primeira versão do SIA aos processos das [duas principais áreas], que eram os mais relacionados à disseminação de informações.

SUPERINTENDENTE: Não é minha visão que [os consultores] patinaram. No âmbito da área 1 , houve desde o início uma facilidade. No universo área 2, não tanto. Isso teve que ser muito bem trabalhado com a equipe, é uma área sensível que precisou de todo esse trabalho. Nos deparamos com uma situação crítica que estava além do projeto em si. Tivemos que trabalhar com pessoas críticas, e isso não é fácil.

ANALISTA DE NEGÓCIO 2: Acho que faltou clareza na definição do escopo. Talvez tenha faltado uma reunião para discutirmos com antecedência até onde iríamos em cada uma daquelas áreas. Essa clareza só conseguimos depois de modelarmos os processos atuais. Em um primeiro momento, pode se pensar que foi um esforço jogado fora. Hoje vemos que não, porque em um outro projeto que está sendo iniciado agora, parte daquele esforço pode ser reaproveitado.

Os consultores ainda não estavam alertas para o fato de que eles não tinham o escopo do sistema definido. Isso fez com que eles saíssem entrevistando todo mundo. As reuniões de levantamento eram feitas com todas as áreas. Todos queriam tudo.
Os processos eram muitos. A equipe percebe que a tarefa era grande demais. Como isso poderia ter sido evitado?

Aqui temos uma divergência de entendimento entre a coordenação e a consultoria. Qual a causa disso? Quem está certo?

A equipe incorpora um novo artefato à "caixa de ferramentas". As reuniões se tornam mais produtivas, mas o caminho ainda não está claro.

Os usuários não ajudavam a equipe. Cada um queria o "seu" problema resolvido. Como os usuários poderiam ser conduzidos para resolver o "nosso" problema?

A solução para o problema de escopo: o projeto focará em duas áreas principais. Mas dois meses já haviam se passado e parte do projeto não seria aproveitada

A falta de clareza no escopo é posta pela coordenação, e a consultoria não consegue ver essa falta. Isto é um bom exemplo do modelo do observador apresentado na figura.4. A escuta e a capacidade de observação de algo passa pelas possibilidades do próprio observador. A coordenação dizia algo, e a consultoria não podia ver. Isto pode até revelar certa falta de competência (e.g., de um escutar mais efetivo), mas é, antes de tudo, um fenômeno humano.

Uma situação aparentemente negativa contém elementos positivos, tais como reconhecer os limites e possibilidades do grupo, do projeto, a criação de novos instrumentos, novas conversações etc. Que se aprende disto? O equilíbrio e a manutenção das redes interacionais vão acomodando e reacomodando informações/ decisões, até que se cria uma base comum de trabalho e percepção. A aceitação das incertezas e contradições do processo contribui para que o espaço de aprendizagem se torne mais propício ao exercício da tentativa.

Esta fase fecha com declarações de abertura e aprendizagem indicando que a conturbação inicial, se aceita e encarada como parte do processo, pode ajudar a estabelecer consensos sólidos e decisões maduras.

Levantamento dos requisitos. A atividade foi facilitada pela ação anterior. $\mathrm{O}$ historiador observa como a equipe reconhece a responsabilidade do usuário pelo resultado do projeto. São observadas possibilidades de mudança, tais como a apresentação de casos como exemplos para experiências futuras. Foi apreciado o alto nível do detalhamento do resultado final, e alguns dos 
participantes observam as dificuldades que, no futuro, isso pode trazer para o desenvolvimento do SIA.

\section{Falando de sistema}

O levantamento de requisitos segue ao de processos. Os requisitos vieram dos processos propostos e marcados como "automatizáveis" no workshop anterior. Como esse projeto tem por objetivo o mapeamento, e não o desenvolvimento do sistema, esse levantamento é feito em alto nível e será utilizado como subsídio futuro para a construção do sistema.

ANALISTA DE NEGÓCIO 2: [...]Realizamos algumas entrevistas com cada uma das gerências das duas principais áreas, e conseguimos capturar requisitos do sistema. [...]Nós levávamos os diagramas de atividades resultantes do workshop de melhoria de processo, e para cada atividade que era passível de automação nós questionávamos: "nesta atividade aqui, o que vocês precisam, como é que vocês querem que essa atividade seja automatizada?"

[...] Uma lição aprendida neste projeto, eu acho, é que durante o levantamento de requisitos, talvez valha a pena nós levarmos alguns exemplos de casos de uso, algumas explanações sobre o que vamos querer como resultado daquelas reuniões.

$\mathrm{Na}$ área 2 eles se envolveram de tal forma, que, no resultado da reunião e das entrevistas, nós praticamente já tínhamos os outline de casos de uso prontos, e isso deu uma agilidade muito grande ao levantamento.

ANALISTA DE NEGÓCIO 1: [...] A solução proposta por nós não ficou limitada só ao desenvolvimento deste sistema, ou no redesenvolvimento dos que já existiam e atendiam parcialmente à necessidade do usuário. Existia uma grande necessidade de realizar consultas com um caráter mais gerencial, consultas que exigem comparação, média, série de dados históricos, e nos levou a propor também uma solução de datawarehouse.[...]

ANALISTA DE NEGÓCIO 2: [...]. Como nós já tínhamos passado de fase, nós só registramos que havia um novo processo e, como estávamos com o prazo no limite, nós optamos por não gastar mais esforços em modelagem de processo. [...]

ANALISTA DE NEGÓCIO 1: é uma dúvida para mim se o usuário soube descrever um sistema que ainda não existia. Como o levantamento de requisitos foi feito em alto nível, para esse propósito eles se saíram bem. Quando eu digo que tenho dúvida, é em saber se o nível de levantamento que foi feito vai precisar ser refinado para o desenvolvimento do sistema. Que de repente um caso de uso desse que levantamos, numa etapa de desenvolvimento, pode originar um novo caso de uso ou dois outro, que seja mais periférico, um de cadastro ou de associação. A funcionalidade macro, core business, foi capturada agora.

A responsabilidade do usuário pelo produto que está nascendo é ressaltada pela equipe

O levantamento de requisitos não tem por objetivo detalhar todas as atividades. O outline dos casos de uso é uma descrição em alto nível que captura seu objetivo geral, sem entrar na interação entre o usuário e o sistema. O mesmo ocorre no projeto do datawarehouse, que pára no levantamento prévio dos datamarts.

O "Visão" descreve o sistema como um todo, servindo de base contratual entre os gestores e a equipe de desenvolvimento.

Com vários meses de projeto, o usuário sente falta de um produto com mais "substância", mesmo que esse tenha sido o acordo inicial. O levantamento em alto nível agrega valor significativo ao processo de desenvolvimento, ou deve-se fazer o detalhamento das funcionalidades de uma vez?

As conversações se revelam como recursos de gestão que geram ganhos coletivos. As falas dos participantes revelam altos graus de amadurecimento, surgem questionamentos e reflexões. Há uma reflexão sobre as condições de satisfação dos gestores, dos usuários e do sistema. Percebe-se a necessidade de aprofundar o conhecimento do impacto do produto sobre o usuário, o que coloca uma ordem ética nas camadas de aprendizagem: a preocupação com o outro se revela, bem como a de melhorar a autogestão pelo registro consolidado, rotina não executada anteriormente pela equipe. Será que estas conversações reflexivas foram abertas? Foram compartilhadas com todos os membros do grupo? Instaurar conversações de reflexão gera possibilidades de aprendizagem e maturidade em equipes.

Fecho do projeto: hora de avaliar. A história apresenta grandes momentos de conversações de aprendizagem. Em vários, reflete-se sobre como fazer diferente, quais as lições aprendidas, revelando o observador que a organização é, na medida em que seus integrantes estão atentos para novas práticas. Pergunta-se se essas 
aprendizagens são registradas e potencializadas para a organização como um todo e, caso a história não tivesse sido contada, se essas aprendizagens seriam aproveitadas. Observamos que algumas conversações não aparecem com freqüência, nem durante nem no final da história. A declaração de visão de futuro é compartilhada e a de satisfação também. A história é rica em aprendizagem e poderosa para ilustrar ciclos de aprendizagem: há uma situação de confusão e conflito inicial que passa por reacomodações sucessivas até gerar aprendizagens profundas.

\section{Sucesso ou fracasso? As avaliações finais são feitas}

Os envolvidos fazem as avaliações finais e a reflexão sobre os pontos positivos e negativos do projeto.

GERENTE DE SISTEMAS: [...] A questão da integração da equipe poderia estar melhor com relação à equipe interna da organização, temos que repensar como introduzir o pessoal da organização mais próximo da consultoria, apesar da defasagem grande de conhecimento da nossa equipe... Poderíamos agregar mais as pessoas sem atrapalhar o processo como um todo ou o resultado.

ANALISTA DE NEGÓCIO 2: A facilidade de relacionamento que o analista 1 tem nas sessões de entrevista foi fundamental. Ele soube cativar os facilitadores, soube trazer os facilitadores para perto do projeto... foi um ponto positivo.

ANALISTA DE NEGÓCIO 1: [...]Conseguimos contornar os problemas de comunicação e rivalidade entre as áreas, promovendo o trabalho conjunto, mostrando que os produtos gerados são para a organização e não para a área X ou Y. Esses fatores e a própria satisfação que temos colhido na validação dos artefatos, nos depoimentos pessoais dos usuários, nos leva a acreditar que o projeto alcançou o objetivo. Apesar de momentos conturbados, no final conseguimos alcançar o objetivo inicialmente definido.

GERENTE DE SISTEMAS: [...] já é possível as pessoas conversarem entre si e verem que um sistema vai sair do outro lado.

A organização deseja que seus profissionais adquiram o conhecimento do processo aplicado pela consultoria. Durante o projeto, essa integração foi tentada, mas não aconteceu. Como esse conhecimento poderia ser transferido?
Nas avaliações finais, confiança, relacionamentos, aceitação aparecem como os principais ativos do projeto. São observadas mudanças de ânimos e atitudes.

Saldo final: sucesso. O que começou motivado por "informação" termina gerando "conhecimento". A história continua no desenvolvimento do projeto

Os participantes apresentam suas opiniões sobre o resultado que, em geral, é satisfatório, e apresenta uma percepção madura e ética, que privilegia as pessoas sem perder de vista o processo em que estão envolvidas.

A avaliação ainda está longe de ser uma conversação de aprendizagem. Para isso, precisa ser compartilhada, de modo a gerar uma ordem de aprendizado de um outro nível no nível do observador, isto é, além de gerar uma competência individual, gerar novas competências na maneira como se gerenciam projetos e especificamente como se interpretam e lidam com as dificuldades inerentes a uma organização e ao fenômeno humano.

Fica a sensação de que a consultoria, o grupo gestor e a organização tiveram oportunidades de aprendizagem poderosas. Algumas delas foram aproveitadas, outras talvez não.

O final desta HA é gratificante: as pessoas percebem nitidamente possibilidades de conversa e sabem que um produto consolidará esse processo. Dessa forma, a trajetória do grupo durante a narrativa é clara: houve um deslocamento e uma modificação na ação, o que caracteriza o movimento de aprendizagem.

\section{CONCLUSÕES}

Uma narrativa pode ser fraca, sem impacto no contexto ou sobre os personagens, ou poderosa, quando faz sentido para outros, gerando conseqüências, significados, mundos, novas possibilidades de ação, enriquecendo, ao mesmo tempo, a compreensão dos fenômenos. Encontramos, durante o processo de análise, o fato de que a narrativa dessa HA oferece várias possibilidades de aprendizagem. No nível de primeira ordem, possibilita ao leitor acompanhar os desafios que o projeto apresentou, verificar se este trouxe ou não aprendizado prático para o grupo e enriquecer-se com o enfoque de cada ator; assim como facilita a observação no nível da ação, uma aprendizagem de como fazer igual ou diferente e, finalmente, permite ver se cada um e o grupo aproveitaram ou não cada experiência como lição aprendida. 
No nível de aprendizagem de segunda ordem, pode ocorrer um aprendizado que amplie os limites de observação e de ação de um observador, melhorando sua capacidade de aprendizagem. Quando surgem reflexões profundas, tal como perceber que uma situação pode ter interpretações diferentes, isso pode igualmente constituir uma mudança profunda na maneira de compartilhar e resolver problemas, gerando maiores espaços de troca e reforçando o papel da confiança na realização de projetos e na consecução dos resultados.

No caso específico da gestão organizacional, a leitura de uma história pode produzir aprendizados no nível da ação dos narradores / participantes / ouvintes / leitores, os quais poderão decidir pelas mesmas ações ou não.

Uma história revela que os grupos, as equipes, as organizações não atuam ao acaso, mas de acordo com o tipo de observador que são. Dessa maneira, é possivel que, por intermédio de uma HA, ao se revelar o tipo de organização por trás da história, abra-se um espaço poderoso de observação e aprendizagem em níveis ainda mais profundos e efetivos. A HA do projeto SIA, por isso, pareceu-nos rica em aprendizados de primeira e segunda ordem, pela diversidade de atores, experiências e visões que fazem dela uma experiência de aprendizado poderosa.

O comprometimento do narrador na história mostra as contradições, as lições aprendidas e, em alguns momentos, questiona como poderia ser diferente. Pensamos que esse seja, talvez, o papel do historiador de uma HA: assumindo o papel de narrador de uma narração, de contador da história da história, de observador mais distanciado e portador de um poder diferenciado de observação, trazer à tona tudo o que ficou oculto aos que viveram a história e aos que a narraram pela primeira vez, transformando-a, de mera narrativa, em instrumento de aprendizagem individual, grupal e organizacional, um instrumento possível e eficaz de gestão. Por sua vez, o papel dos analistas, observando o que foi vivido e contado, ontologicamente contribui para novas percepções de si, do outro, das relações e dos impactos dessas redes sobre seus contextos e integrantes. Já hermeneuticamente, a análise de uma HA constitui um esforço de integração / compreensão entre o passado, o presente e o futuro, esforço em que os implicados iniciais (personagens) tornam-se elos envolvendo os observadores, os quais passam a ser os novos personagens da História da História de Aprendizagem, e da História da História da História de Aprendizagem, em tantos desdobramentos quantos forem os novos momentos de observação. Tanto na vertente ontológica quanto na hermenêutica, a análise seria o passo necessário à instauração de novos níveis de observação e, portanto, de possibilidades de aprendizagem, tanto para os indivíduos, quanto para os grupos e organizações.

A natureza dessa aprendizagem varia de acordo com o tipo de observador que o indivíduo, o grupo ou a organização são e / ou se tornam, e, se as HA passassem a ser usadas como um dos instrumentos de gestão organizacional, acreditamos que poderiam contribuir para que os participantes das ações se tornassem mais conscientes de suas possibilidades e restrições, melhorando o conhecimento do contexto em que essas ações se dão e, conseqüentemente, de si próprios como seus atores e dos cenários onde se movem.

Artigo submetido em 03/11/2008 e aceito em 22/12/2008.

\section{REFERÊNCIAS}

1. ABMA, T. A. Storytelling as inquiry in a mental hospital. Qualitative Health Research, v. 8, n. 6, p. 821-838, 1998.

2. ARGYRIS, Chris. Kwowledge for action: a guide to overcoming barriers to organizational change. San Francisco: Jossey-Bass, 1993.

3. BROWN, John Seely. A vida social da informação. São Paulo: Makron Books, 2001.

4. BRUNER, J. Actual minds, possible words. Cambridge: Harvard University Press, 1986.

5. ECHEVERríA, Rafael. Ontología del lenguaje. 6. ed. Santiago, Chile: J.C. SÁEZ, 2003.

6. _-_-_. Sobre el coaching ontológico. 4. ed. Buenos Aires: Gran Aldea, 2005.

7. FLORES, Fernando. Management and communication in the office of the future. 1979. Tese (Doutorado)- University of Berkeley, California, 1979.

8. FONSECA, F. The double role of ontologies in Information Science. Journal of the American Society for Information Science and Technology, v. 58, n. 6, p. 786-793, 2007.

9. GEANELLOS, Rene. Exploring ricoeur's hermeneutic theory of interpretation as a method of analyzing research texts. Nursing Inquiry, v. 7, p. 112-9, 2000.

10. GEERTZ, C. Local knowledge: further essays in interpretive anthropology. New York: Basic, 1983.

11. GUARINO, N. Formal ontology and information systems: formal ontology in information systems. Netherlands: IOS Press, 1998.

12. LABOV, W.; WALETSKY, J. Narrative analysis: oral versions of personal experience. In: HELM, J. (Ed.). Essays on the verbal and visual art. San Francisco: American Ethnological Society, 1967. 
Histórias de aprendizagem e gestão organizacional: uma abordagem ontológica e hermenêutica

13. RICOEUR, Paul. The hermeneutical function of distanciation. Philosophy Today, v. 17, n. 2/4, p. 129-41, 1973.

14. The conflicts of interpretations: essays in hermeneutics. Evanston: North-western University Press, 1974.

15. From text to action: essays in hermeneutics II. London The Athlone Press, 1991.

16. _-_-_. Hermeneutics and the human sciences. Cambridge, Massachusetts: Cambridge University Press, 1995.

17. REISSMAN, Catherine K. Narrative analysis. Thousand Oaks, CA: Sage Publications, 1993.

18. SCHAFER, Roy. Listening in psychoanalysis. Narrative, v. 13, n. 3, Oct. 2005 .
19. SENGE, Peter. A quinta disciplina: arte e prática da organização que aprende. 17. ed. São Paulo: Nova Cultural, 1990.

20. TORRES, Alexandre Henrique de S.; ANQUETIL, Nicolas; OLIVEIRA, Káthia M. de. Pro-active dissemination of knowledge with learning histories. In: LEARNING SOFTWARE ORGANIZATION (LSO2006). Rio de Janeiro: [s.n], 2006.

21.TODOROV, Tzvetan. A poética da prosa. 2. ed. São Paulo: Edições $70,1979$.

22. USCHOLD, M; GRUNINGER, M. Ontologies: principles, methods and applications. Knowledge Engineering Review, v. 11, n. 2, 1996. 